\title{
NOTES
}

\section{Efficient Cobalt Complex on the Reaction between Isophorone Diisocyanate and Diethylene Glycol}

\author{
Shin-ichi INOUE ${ }^{\dagger}$ and Yasuharu NAGAI \\ Department of Applied Chemistry, Aichi Institute of Technology, \\ 1247 Yachigusa, Yakusa-cho, Toyota 470-0392, Japan
}

(Received November 11, 2004; Accepted February 2, 2005; Published May 15, 2005)

\author{
KEY WORDS Isophorone Diisocyanate / Diethylene Glycol / Cobalt(II) Hexafluoroacethylaceto- \\ nate / Polyaddition / Polyurethane / \\ [DOI 10.1295/polymj.37.380]
}

Polyurethane is widely used for new industrial materials. However, there is the problem of polyurethane prepared from aromatic isocyanates being colored by air and light. In order to solve this problem, aliphatic isocyanates, which are resistant to coloring by air and light, are used. However, it is already clear that aliphatic isocyanates are less reactive than aromatic isocyanates and they are not able to use conventional catalysts such as tertiary amines ${ }^{1-5}$ in the reaction between aliphatic isocyanates and alcohols. Although dibutyltin dilaurate (DBTDL) is generally used as a catalyst, ${ }^{6-8}$ this compound contains a little tributyltin which is notable for environmental contamination. Accordingly, it is unfavorable to use it as catalyst. Thus, the development of a new catalyst having a high catalytic activity is necessary. ${ }^{9}$ Recently, a new group (or type) of catalysts, late transition metal complexes, are being researched with great interest as catalysts. ${ }^{10,11}$ In particular, metal- $\beta$-diketone complexes $\left(\mathrm{Mt}(\mathrm{acac})_{n}\right)$ are gaining much attention. For example, $\mathrm{Fe}(\mathrm{acac})_{3}$ and $\mathrm{Cu}(\mathrm{acac})_{2}$ complexes are used in the reaction between hexamethylene diisocyanate (HDI) and alcohols. ${ }^{12,13}$ We have also already reported that $\mathrm{Mt}(\mathrm{acac})_{n}$ and tertiary amine-Mt(acac $)_{n}$ complexes had adjective catalytic activity on the reaction between HDI and diethylene glycol (DEG). ${ }^{14}$

In the present paper, the catalytic activities and kinetics of $\mathrm{Mt}(\mathrm{acac})_{n}$ and $\mathrm{Co}\left(\mathrm{f}_{6} \mathrm{acac}\right)_{2}-\mathrm{Co}(\mathrm{acac})_{2}$ complexes, on the reaction between isophorone diisocyanate (IPDI) and DEG are described. The resulting data clearly shows that the catalytic activity of $\mathrm{Co}\left(\mathrm{f}_{6} \mathrm{acac}\right)_{2}-\mathrm{Co}(\mathrm{acac})_{2}$ complex is the very highest on the reaction between IPDI and DEG.

\section{EXPERIMENTAL}

\section{Materials}

Isophorone diisocyanate (IPDI, Nacalai Tesque Inc.) and diethylene glycol (DEG, Nacalai Tesque Inc.) were distilled immediately under reduced pressure $\left(1 \mathrm{mmHg}\right.$ ) before use. Manganese(II) $\left(\mathrm{Mn}(\mathrm{acac})_{2}\right)$ and iron(III) acethylacetonates $\left(\mathrm{Fe}(\mathrm{acac})_{3}\right)$ were obtained from Nacalai Tesque Inc. Cobalt(II) (Co$\left.(\text { acac })_{2}\right)$, nickel(II) $\left(\mathrm{Ni}(\mathrm{acac})_{2}\right)$, and copper(II) acethylacetonates $\left(\mathrm{Cu}(\mathrm{acac})_{2}\right)$, cobalt(II) hexafluoroacethylacetonate $\left(\mathrm{Co}\left(\mathrm{f}_{6} \mathrm{acac}\right)_{2}\right)$ and dibutyltin dilaurate (DBTDL) were obtained from Tokyo Kasei Kogyo Co., Ltd. and used without further purification. Toluene (Nacalai Tesque Inc.) and $N, N$-dimethylformamide (DMF, Nacalai Tesque Inc.) were dehydrated over a molecular sieve $(4 \AA)$. Other reagents are commercially available and were used as received.

Reaction Catalyzed by $\mathrm{Co}\left(f_{6} \text { acac }\right)_{2}-\mathrm{Co}(\text { acac })_{2}$ Complex between Isophorone Diisocyanate and Diethylene Glycol

A DMF solution containing a catalyst and a isocyanate was prepared from $\mathrm{Co}(\mathrm{acac})_{2}(0.0798 \mathrm{~g}, 0.31$ $\mathrm{mmol}), \quad \mathrm{Co}\left(\mathrm{f}_{6} \mathrm{acac}\right)_{2} \quad(0.0376 \mathrm{~g}, \quad 0.08 \mathrm{mmol})$, IPDI $(1.38 \mathrm{~g}, 6.20 \mathrm{mmol})$ and $\mathrm{DMF}(15 \mathrm{~mL})$, and this DMF solution was degassed under an argon atmosphere. DEG $(0.66 \mathrm{~g}, 6.20 \mathrm{mmol})$ and DMF $(70 \mathrm{~mL})$ solutions were placed in a $200 \mathrm{~mL}$ three-necked round bottom flask fitted with a mixer and an argon inlet tube, and then the resulting solution was stirred vigorously at the desired reaction temperature (for example $30^{\circ} \mathrm{C}$ ) for $30 \mathrm{~min}$ under an argon atmosphere. The reaction was started by addition of the DMF solution containing the catalyst and the isocyanate to DEG-DMF solution. Aliquots $(8 \mathrm{~mL})$ were produced

${ }^{\dagger}$ To whom correspondence should be addressed (E-mail: sh-inoue@aitech.ac.jp). 
from the reaction mixture at regular time intervals $(5$ or $10 \mathrm{~min}$ ), and it was added to a predetermined excess of $1 \mathrm{M}$ di-n-dibulylamine solution $(10 \mathrm{~mL})$. The unreacted amine was back-titrated to a bromocresol green end-point by using standard hydrochloric acid solution $(0.5 \mathrm{M})$. The rate constant $(k)$ was calculated on the basis of simple second-order kinetics.

\section{Characterization}

IR spectra (in $\mathrm{KBr}$ pellets) were recorded on a JASCO FT/IR-5300 spectrometer.

\section{RESULTS AND DISCUSSION}

Table I summarizes the reactions catalyzed by various complexes such as $\mathrm{Mt}(\mathrm{acac})_{n}$ between IPDI and DEG. From the theory of Farkas ${ }^{3}$ and Hostettler, ${ }^{4}$ the catalytic constant $\left(K_{\mathrm{c}}\right)$ was calculated from the following equation:

$$
k=k_{0}+K_{\mathrm{c}}[\text { catalyst }]^{n} .
$$

and the rate constants $\left(k_{0}\right.$ : uncatalyzed reaction and $k$ : catalyzed reaction) were calculated on the basis of simple second-order kinetics. The reaction between IPDI and DEG did not proceed without a catalyst. However, when $\operatorname{Mt}(\mathrm{acac})_{n}$ was used as a catalyst on this reaction, the reaction proceeded speedily. The $\mathrm{Mn}(\mathrm{acac})_{2}$ catalyst reached a high conversion $(>80 \%)$ after $120 \mathrm{~min}$, whereas DBTDL showed $<70 \%$ conversion after $120 \mathrm{~min}$. In addition, the catalytic activity of $\mathrm{Mn}(\mathrm{acac})_{2}$ was very high and it was more active than that of DBTDL. When the $\operatorname{Mt}(\mathrm{acac})_{n}$ was used as catalysts, the resulting product, polyurethane, was colored by the catalytic color. For example, $\mathrm{Mn}(\mathrm{acac})_{2}$ was yellow ocher and $\mathrm{Fe}(\mathrm{acac})_{3}$ was red. If the colorless polyurthane elastomer need, it is unfavorable to use $\mathrm{Mt}(\mathrm{acac})_{2}$ and $\mathrm{Mt}(\mathrm{acac})_{3}$ complexes. Therefore, $\mathrm{Mt}\left(\mathrm{f}_{6} \mathrm{acac}\right)_{n}-\mathrm{Mt}(\mathrm{acac})_{n}$ complex was examined. The effect of $\mathrm{f}_{6}$ acac ligand to the reaction was reported already by Nahlovsky. ${ }^{15}$ Thus, $\operatorname{Co}\left(\mathrm{f}_{6} \mathrm{acac}\right)_{2}-\mathrm{Co}(\mathrm{acac})_{2}$ complex was particularly selected in here.

Table I. The polyaddition reactions catalyzed by $\operatorname{Mt}(\mathrm{acac})_{n}$ complexes between IPDI and $\mathrm{DEG}^{\mathrm{a}}$

\begin{tabular}{lcc}
\hline \multicolumn{1}{c}{ Catalyst } & $k / \mathrm{L} \mathrm{mol}^{-1} \mathrm{~h}^{-1}$ & $K_{\mathrm{c}} \times 10^{3} / \mathrm{L}^{2} \mathrm{eq}^{-1} \mathrm{~mol}^{-1} \mathrm{~h}^{-1}$ \\
\hline none & 1.8 & - \\
$\mathrm{DBTL}$ & 31.7 & 8.3 \\
$\mathrm{Mn}(\mathrm{acac})_{2}$ & 35.5 & 9.4 \\
$\mathrm{Fe}(\mathrm{acac})_{3}$ & 11.7 & 2.8 \\
$\mathrm{Co}(\mathrm{acac})_{2}$ & 14.3 & 3.5 \\
$\mathrm{Ni}(\mathrm{acac})_{2}$ & 2.1 & - \\
$\mathrm{Cu}(\mathrm{acac})_{2}$ & 1.5 & - \\
\hline
\end{tabular}

${ }^{\mathrm{a}}[$ Catalyst $]=0.0036 \mathrm{~mol} \mathrm{~L}^{-1}, \quad[\mathrm{HDI}]=[\mathrm{DEG}]=0.073$ mol L ${ }^{-1}$, Temp. $=30^{\circ} \mathrm{C}$, solvent $=$ DMF.
Table II. The polyaddition reactions catalyzed by $\mathrm{Co}\left(\mathrm{f}_{6} \mathrm{acac}\right)_{2} / \mathrm{Co}(\mathrm{acac})_{2}$ complexes between IPDI and $\mathrm{DEG}^{\mathrm{a}}$

\begin{tabular}{lcc}
\hline \multicolumn{1}{c}{ Catalyst } & $k / \mathrm{L} \mathrm{mol}^{-1} \mathrm{~h}^{-1}$ & $K_{\mathrm{c}} \times 10^{3} / \mathrm{L}^{2} \mathrm{eq}^{-1} \mathrm{~mol}^{-1} \mathrm{~h}^{-1}$ \\
\hline none & 1.8 & - \\
DBTL & 31.7 & 8.3 \\
$\mathrm{Co}(\mathrm{acac})_{2}$ & 14.3 & 3.4 \\
$\mathrm{Co}\left(\mathrm{f}_{6} \mathrm{acac}\right)_{2}$ & - & - \\
$\mathrm{Co}\left(\mathrm{f}_{6} \mathrm{acac}\right)_{2} / \mathrm{Co}(\mathrm{acac})_{2} *$ & 36.9 & 9.8 \\
\hline
\end{tabular}

${ }^{\mathrm{a}}[$ Catalyst $]=0.0036 \mathrm{~mol} \mathrm{~L}^{-1}, \quad[\mathrm{HDI}]=[\mathrm{DEG}]=0.073$ mol L ${ }^{-1}$, Temp. $=30^{\circ} \mathrm{C}$, solvent $=\mathrm{DM} . \quad * \mathrm{Co}\left(\mathrm{f}_{6} \mathrm{acac}\right)_{2} / \mathrm{Co}-$ $(\mathrm{acac})_{2}=0.25$.

Table II summarizes the reactions catalyzed by $\mathrm{Co}\left(\mathrm{f}_{6} \mathrm{acac}\right)_{2}-\mathrm{Co}(\mathrm{acac})_{2}$ complex (a molar ratio: $\left.\mathrm{Co}\left(\mathrm{f}_{6} \mathrm{acac}\right)_{2} / \mathrm{Co}(\mathrm{acac})_{2}=0.25\right)$ between IPDI and DEG. The reaction catalyzed by only $\operatorname{Co}\left(\mathrm{f}_{6} \mathrm{acac}\right)_{2}$ complex did not proceeded, and the $\operatorname{Co}\left(\mathrm{f}_{6} \mathrm{acac}\right)_{2} \mathrm{com}-$ plex was inactive on this reaction. However, when $\mathrm{Co}\left(\mathrm{f}_{6} \mathrm{acac}\right)_{2}$ and $\mathrm{Co}(\mathrm{acac})_{2}$ complexes were used together, the resulting complex, $\mathrm{Co}\left(\mathrm{f}_{6} \mathrm{acac}\right)_{2}-\mathrm{Co}(\mathrm{acac})_{2}$, showed a high catalytic activity on the reaction between IPDI and DEG, and it was higher than that of DBTDL and $\mathrm{Mn}(\mathrm{acac})_{2} \cdot \operatorname{Co}\left(\mathrm{f}_{6} \mathrm{acac}\right)_{2}$ was used as a co-catalyst. It is clear that the existence of a co-catalyst such as $\mathrm{Co}\left(\mathrm{f}_{6} \mathrm{acac}\right)_{2}$ was important to this reaction and the product obtained on the reaction catalyzed by $\mathrm{Co}\left(\mathrm{f}_{6} \mathrm{acac}\right)_{2}-\mathrm{Co}(\mathrm{acac})_{2}$ complex was colorless and transparent. In addition, the molar ratio of $\mathrm{Co}\left(\mathrm{f}_{6} \mathrm{acac}\right)_{2}$ and $\mathrm{Co}(\mathrm{acac})_{2}$ complexes was examined, and the results are shown in Figure 1. The activity of catalyst in the reaction was dependent on the molar ratio of $\mathrm{Co}\left(\mathrm{f}_{6} \mathrm{acac}\right)_{2}$ and $\mathrm{Co}(\mathrm{acac})_{2}$ complexes. When $\mathrm{Co}\left(\mathrm{f}_{6} \mathrm{acac}\right)_{2} / \mathrm{Co}(\mathrm{acac})_{2}$ was 0.25 , the activity of this catalyst was the highest. It was higher than that of DBTDL and $\mathrm{Mn}(\mathrm{acac})_{2}$ complex. The time-reciprocal

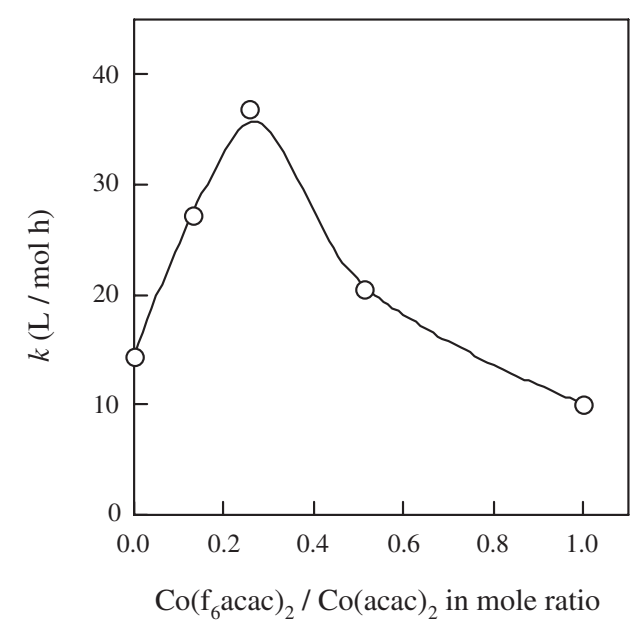

Figure 1. Effect of the $\operatorname{Co}\left(\mathrm{f}_{6} \mathrm{acac}\right)_{2} / \mathrm{Co}(\mathrm{acac})_{2}$ molar ratio on the reation between IPDI and DEG: $[\mathrm{IPDI}]=[\mathrm{DEG}]=0.073$ $\mathrm{mol} / \mathrm{L} ;\left[\mathrm{Co}(\mathrm{acac})_{2}\right]=0.0036 \mathrm{~mol} / \mathrm{L}$. 


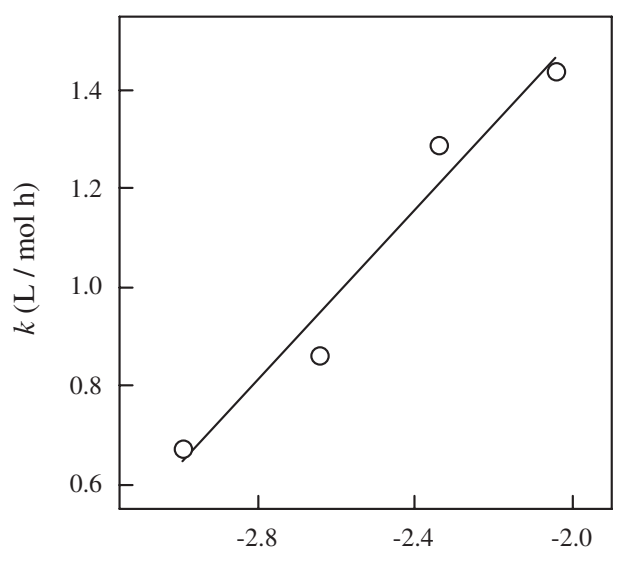

$\log \left[\mathrm{Co}\left(\mathrm{f}_{6} \mathrm{acac}\right)_{2}-\mathrm{Co}(\mathrm{acac})_{2}(\mathrm{~mol} / \mathrm{L})\right]$

Figure 2. Dependence of the $k$ on the $\mathrm{Co}\left(\mathrm{f}_{6} \mathrm{acac}\right)_{2}-\mathrm{Co}(\mathrm{acac})_{2}$ catalyst concentration $([\mathrm{IPDI}]=[\mathrm{DEG}]=0.073 \mathrm{~mol} / \mathrm{L}, \quad \mathrm{Co}-$ $\left(\mathrm{f}_{6} \mathrm{acac}\right)_{2} / \mathrm{Co}(\mathrm{acac})_{2}=0.25$ in mole ratio, Temp. $=30^{\circ} \mathrm{C}$, Solvent $=\mathrm{DMF}$ ).

of isocyanate concentration plots observed in the temperature range $30-50{ }^{\circ} \mathrm{C}$. At the next kinetically investigation, the reciprocal of isocyanate concentration linearly increased with the reaction time. From an Arrhenious plot of the $k$ on this reaction, the overall activation energy $\left(E_{\mathrm{a}}\right)$ of the reaction between IPDI and DEG was calculated to be $67.6 \mathrm{~kJ} / \mathrm{mol}$. In the case of DBTDL, the $E_{\mathrm{a}}$ was calculated to be $73.8 \mathrm{~kJ} / \mathrm{mol}$. The $E_{\mathrm{a}}$ of $\mathrm{Co}\left(\mathrm{f}_{6} \mathrm{acac}\right)_{2}-\mathrm{Co}(\mathrm{acac})_{2}$ complex was somewhat lower than that of DBTDL.

Figure 2 presents the relationship between the $k$ and the catalyst concentration $\left(\left[\mathrm{Co}\left(\mathrm{f}_{6} \mathrm{acac}\right)_{2}-\mathrm{Co}(\mathrm{acac})_{2}\right]\right)$. The plot of $\log \left(k / k_{0}-1\right)$ vs. $\log \left[\mathrm{Co}\left(\mathrm{f}_{6} \mathrm{acac}\right)_{2}-\mathrm{Co}-\right.$ $(\text { acac })_{2}$ ] indicated a linear relation between the $k$ and $\left[\mathrm{Co}\left(\mathrm{f}_{6} \mathrm{acac}\right)_{2}-\mathrm{Co}(\mathrm{acac})_{2}\right]$. The $k$ was proportional to the 0.86 power of the $\mathrm{Co}\left(\mathrm{f}_{6} \mathrm{acac}\right)_{2}-\mathrm{Co}(\mathrm{acac})_{2}$ concentration. From these results, the $k$ is expressed as follows:

$$
k=k_{0}+K_{\mathrm{c}}\left[\mathrm{Co}\left(\mathrm{f}_{6} \mathrm{acac}\right)_{2} / \operatorname{Co}(\mathrm{acac})_{2}\right]^{0.86}
$$

We also examined about $\mathrm{Co}(\mathrm{acac})_{2}$ complex, the $k$ was proportional to the 0.84 power of the $\mathrm{Co}(\mathrm{acac})_{2}$ concentration. The 0.86 power observed here is nearly equal to the 0.84 observed for the reaction catalyzed by $\mathrm{Co}(\mathrm{acac})_{2}$. The FT/IR spectra (in $\mathrm{KBr}$ pellets) of 1:1 mixture of IPDI and $\mathrm{Co}(\mathrm{acac})_{2}$ (a), 1:1 mixture of IPDI and $\mathrm{Co}\left(\mathrm{f}_{6} \mathrm{acac}\right)_{2}-\mathrm{Co}(\mathrm{acac})_{2}$ (a molar ratio: $\left.\mathrm{Co}\left(\mathrm{f}_{6} \mathrm{acac}\right)_{2} / \mathrm{Co}(\mathrm{acac})_{2}=0.25\right)(\mathrm{b})$, and $1: 1$ mixture of IPDI and $\mathrm{Co}\left(\mathrm{f}_{6} \mathrm{acac}\right)_{2}$ (c) were found with appearance of the NCO peak at $2265 \mathrm{~cm}^{-1}, 2267 \mathrm{~cm}^{-1}$ and $2269 \mathrm{~cm}^{-1}$ (Figure 3). The additional effect of Co$\left(\mathrm{f}_{6} \mathrm{acac}\right)_{2}$ complex to Co(acac $)_{2}$ complex was involved with an upward shift $2 \mathrm{~cm}^{-1}$ in NCO peak. Although the relation between the NCO peak shift value and an affinity for complex was not clear, this behavior

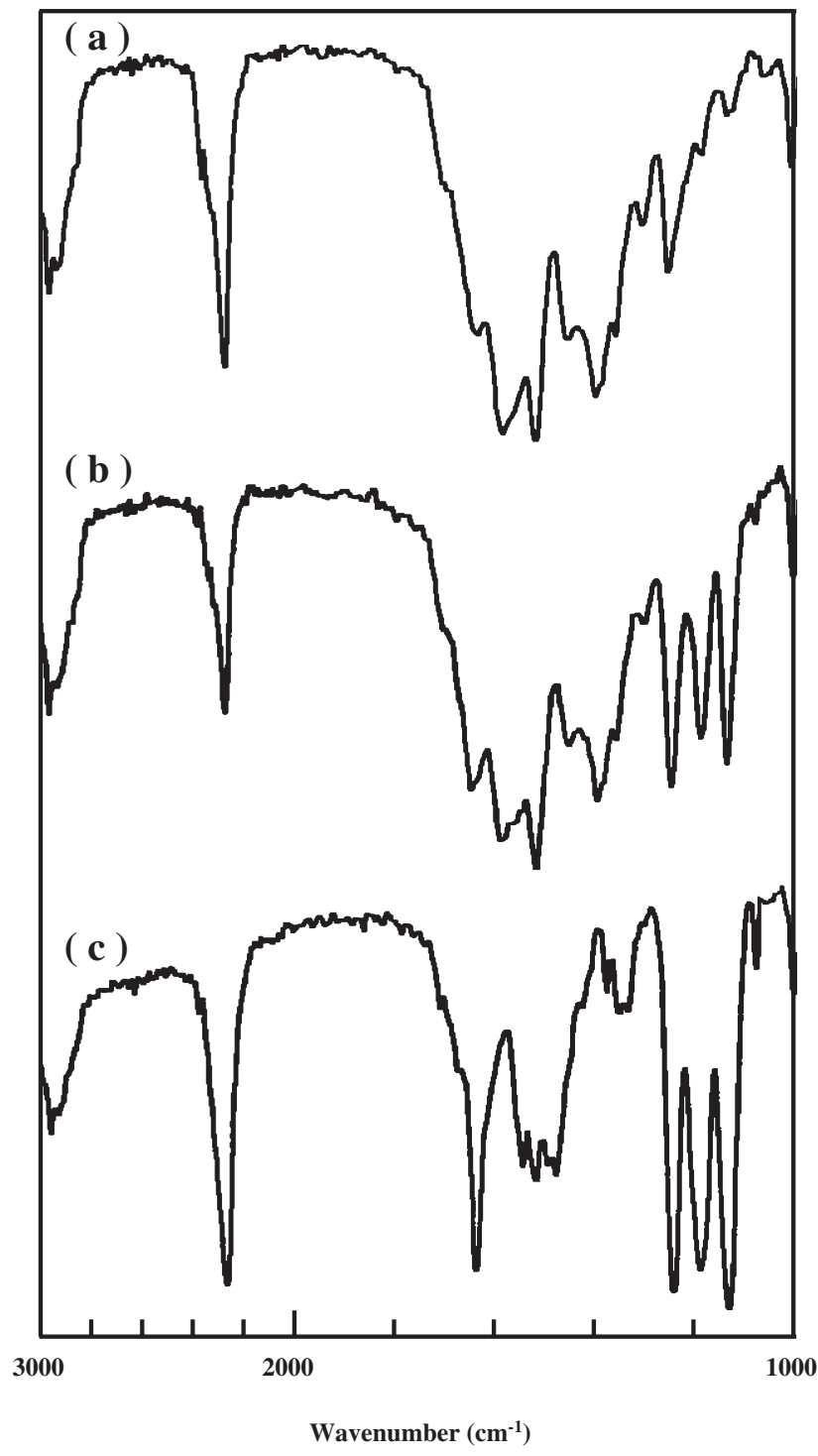

Figure 3. IR spectra of IPDI-Co complexes: (a) IPDI-Co$(\mathrm{acac})_{2}$ complex, (b) IPDI-Co(f $\left.\mathrm{f}_{6} \mathrm{acac}\right)_{2}-\mathrm{Co}(\mathrm{acac})_{2}$ complex (Co$\left.\left(\mathrm{f}_{6} \mathrm{acac}\right)_{2} / \mathrm{Co}(\mathrm{acac})_{2}=0.25\right)$, (c) IPDI-Co(f $\left.\mathrm{f}_{6} \mathrm{acac}\right)$ complex.

was due to the different active species. In the future, the behavior is clarified from further investigation.

\section{REFERENCES}

1. J. Burkas and C. F. Eckert, J. Am. Chem. Soc., 80, 5948 (1958).

2. B. G. Alzner and K. C. Frisch, Ind. Eng. Chem., 51, 715 (1959).

3. A. Farkas and K. G. Flynn, J. Am. Chem. Soc., 82, 642 (1960).

4. F. Hostettler and E. F. Cox, Ind. Eng. Chem., 52, 609 (1960).

5. J. Burkus, J. Org. Chem., 26, 779 (1961).

6. E. P. Squiller and J. W. Rosthauser, Polym. Mater. Sci. Eng., 55, 640 (1986).

7. R. Lomölder, F. Plogmann, and P. Speier, J. Coat. Technol., 69, 51 (1997).

8. R. Lomoelder, F. Plogmann, and P. Speier, Paint India, 48, 
31 (1998).

9. K. K. Majumdar, A. Kundu, I. Das, and S. Roy, Appl. Organometal. Chem., 14, 79 (2000).

10. G. Anzuino, A. Pirro, G. Rossi, and L. P. Friz, J. Polym. Sci., Polym. Chem. Ed., 13, 1667 (1975).

11. S. Dabi and A. Zilkna, Eur. Polym. J., 16, 475 (1979).

12. R. A. Ligabue, A. L. Monteiro, R. F. de Souza, and M. O. de
Souza, J. Mol. Catal. A: Chem., 130, 101 (1998).

13. R. A. Ligabue, A. L. Monteiro, R. F. de Souza, and M. O. de Souza, J. Mol. Catal. A: Chem., 157, 73 (2000).

14. S. Inoue, Y. Nagai, and H. Okamoto, Polym. J., 34, 1 (2002).

15. B. D. Nahlovsky and G. A. Zimmermun, Int. Jahrestag. Frannhofer-Inst. Treib-Explosivst. 18th Techol. Energ. Mater., 39/1-39/12 (1987). 